\title{
Epidemiological, biochemical and antimicrobial susceptibility characteristics of Streptococcus pseudoporcinus isolated in Quebec, Canada, from 1997 to 2006
}

Correspondence

Christiane Gaudreau

christiane.gaudreau.chum@

ssss.gouv.qc.ca

Received 16 March 2007

Accepted 26 August 2007

\author{
Christiane Gaudreau, ${ }^{1}$ Esther Simoneau, ${ }^{1}$ Olivia Labrecque, ${ }^{2}$ \\ Robert A. Laurence, ${ }^{3}$ Céline Laferrière, ${ }^{4}$ Mark Miller, $^{5}$ Lélia Raynal $^{3}$ \\ and Fabien Rallu ${ }^{4}$
}

\author{
${ }^{1}$ Centre Hospitalier de I'Université de Montréal (CHUM) - Hôpital Saint-Luc, Montréal, \\ OC H2X 3J4, Canada \\ ${ }^{2}$ Faculté de Médecine Vétérinaire, Université de Montréal, Saint-Hyacinthe, OC, Canada \\ ${ }^{3}$ Laboratoire de Santé Publique du Québec, Sainte-Anne-de-Bellevue, OC, Canada \\ ${ }^{4}$ Hôpital Sainte-Justine, Montreal, OC, Canada \\ ${ }^{5}$ Jewish General Hospital, Montreal, QC, Canada
}

\begin{abstract}
From 1997 to 2006, in the province of Quebec, Canada, 15 isolates of Streptococcus pseudoporcinus from 1 urine and 14 vaginorectal cultures were recovered from the genitourinary tract of pregnant women. All these women originated from the Caribbean or sub-Saharan Africa ( $P=0.00045$ compared with a suitable control group). The $S$. pseudoporcinus isolates were compared to eight isolates of Streptococcus porcinus identified in Quebec from 1995 to 2006, all from animals, of which five were swine. 16S rRNA gene sequencing was required to differentiate between $S$. pseudoporcinus and S. porcinus animal isolates.
\end{abstract}

\section{INTRODUCTION}

Streptococcus porcinus is a $\beta$-haemolytic Streptococcus of Lancefield groups E, P, V, U, NG1 (A1, C1), NG2 and NG3 (Facklam et al., 1995; www.bacdico.net). This $\beta$-haemolytic Streptococcus was first isolated from swine in 1937. The species S. porcinus was formally described in 1985 (Collins et al., 1984). The main reservoir of $S$. porcinus is swine, but it has also been isolated from other animals, such as cattle, sheep, guinea pigs, rabbits and dogs. In swine, this bacterium colonizes the upper respiratory and genital tracts, and has been responsible for septicaemia, adenitis, cellulitis and abortions (Wessman, 1986). Since 1960, 32 human S. porcinus cases have been reported: 22 in women, 3 in men and 7 for which patient gender was not stated (Duma et al., 1969; Parker \& Ball, 1976; Colman \& Ball, 1984; Facklam et al., 1995; Martin et al., 2004; Duarte et al., 2005). Eighteen strains were isolated from the genitourinary tract (amniotic liquid, placenta, cervix, vagina or urine), six from wounds, three from blood, one from the umbilicus, and for the remaining four the isolation site was not recorded. They were associated with chorioamnionitis or post-partum endometritis, cutaneous infection in two

Abbreviations: CAMP, Christie-Atkins-Munch-Petersen; CDC, Centers for Disease Control and Prevention; GBS, group B streptococcus. meat workers, and septicaemia in a female, a male and a newborn. The clinical picture was not well-established for many cases. The Lancefield group was known for 28 of them: 23 were group C1, 2 were group E, and 3 were group P. Recently, using $16 \mathrm{~S}$ rRNA gene sequencing, our own $S$. porcinus-like isolates recovered from the genitourinary tract of women were shown to represent a new species, Streptococcus pseudoporcinus (Bekal et al., 2006). This new species was recently formally recognized (Euzéby, 2007).

The objectives of this study were to describe the epidemiology, and to determine the biochemical and antimicrobial susceptibility characteristics, of $15 \mathrm{~S}$. pseudoporcinus isolated in Quebec, Canada, from 1997 to 2006.

\section{METHODS}

16S rRNA gene sequencing (Bekal et al., 2006) was done for all animal and human isolates identified biochemically as $S$. porcinus at the Laboratoire de Santé Publique du Québec, CHUM - Hôpital SaintLuc and the Faculté de Médecine Vétérinaire de l'Université de Montréal. At CHUM - Hôpital Saint-Luc, the following tests were performed on all isolates: bile aesculin and aesculin hydrolysis tests, susceptibility to bacitracin (0.04 IU disc) test and the ChristieAtkins-Munch-Petersen (CAMP) test read after 18 to $24 \mathrm{~h}$ (Facklam et al., 1995). Mannitol and sorbitol purple broths $(5 \mathrm{ml})$ were read after 18 to $24 \mathrm{~h}$ of incubation. PathoDx grouping for $\beta$-haemolytic 
Streptococcus were completed. The 118 group B streptococcus (GBS) isolated at CHUM - Hôpital Saint-Luc in August and September 2004 (1 strain per patient) were studied for haemolysis on $5 \%$ sheep blood agar plates and with the following biochemical tests: aesculin hydrolysis, and acidification of mannitol and sorbitol purple broths. At Hôpital Sainte-Justine, PCR of the $c f b$ gene (encoding CAMP factor) (Rallu et al., 2006) was undertaken for the first $11 S$. pseudoporcinus isolates and for the $8 \mathrm{~S}$. porcinus isolates. Susceptibility testing was conducted by the disc diffusion method, as standardized by the Clinical and Laboratory Standards Institute for Streptococcus spp. (CLSI, 2005), and Etest, as recommended by the manufacturer. The following discs were used: penicillin (10 IU), erythromycin $(15 \mu \mathrm{g})$, clindamycin $(2 \mu \mathrm{g})$, tetracycline $(30 \mu \mathrm{g})$, vancomycin $(30 \mu \mathrm{g})$ and trimethoprim $(1.25 \mu \mathrm{g})$-sulfamethoxazole $(23.75 \mu \mathrm{g})$ (BBL; Becton Dickinson). The isolates were grown on 5\% sheep blood agar plates at $37^{\circ} \mathrm{C}$ for $24 \mathrm{~h}$ in an aerobic atmosphere. The following microbiological data were obtained: isolation site, date of positive culture and the laboratory where the strains were isolated. Epidemiological data on the patients included sex, age, ethnic origin, the time since they left their country of origin, complications of pregnancy, and status of the newborn. At CHUM - Hôpital SaintLuc, we undertook a case-control study of six women colonized with S. pseudoporcinus compared with women who delivered on the same day and for whom vaginorectal swab specimens were submitted for GBS culture. The significance of the differences was analysed by Fisher's exact 2-tailed test with Epi Info 2002 software [Centers for Disease Control and Prevention (CDC), Atlanta, GA, USA]. $P$ values of 0.05 or less were considered to be statistically significant.

\section{RESULTS AND DISCUSSION}

A total of 14 human S. porcinus isolates, 13 isolated from vaginorectal swab specimens submitted to the clinical laboratory for GBS culture and 1 from urine, underwent biochemical tests because they had a wide $\beta$-haemolytic zone on 5\% sheep blood agar plates and gave positive agglutination with group B but not with groups A, C, F and G with PathoDx streptococcal antisera. The 15th human $S$. porcinus, isolated from a vaginorectal specimen, was suspected to be of this species because of its large $\beta$ haemolysis without agglutination with group A, B, C, F and $\mathrm{G}$ antisera. $16 \mathrm{~S}$ rRNA sequencing of the $23 \mathrm{~S}$. porcinus isolated in the province of Quebec showed a very homogeneous bacterial cluster for 15 human isolates that was significantly different from the 8 animal isolates thus identifying a new species, S. pseudoporcinus (Bekal et al., 2006; unpublished results). The data from biochemical tests for S. pseudoporcinus in comparison to GBS and $S$. porcinus are reported in Table 1. The 15 S. pseudoporcinus isolates were mannitol-, sorbitol- and aesculin-positive, the 118 GBS isolates were mannitol- and sorbitol-negative and 117 were aesculin-negative. The cultural and biochemical characteristics of the eight $S$. porcinus isolates were similar to those of $S$. pseudoporcinus. All the S. pseudoporcinus isolates were susceptible to penicillin, erythromycin, clindamycin, vancomycin and trimethoprim-sulfamethoxazole; 14 isolates were resistant and 1 isolate was susceptible to tetracycline. The range of diameters obtained by the disc diffusion method and the range of MICs by Etest for S. pseudoporcinus are reported in Table 2. All S. porcinus isolates were susceptible to penicillin, vancomycin and trimethoprim-sulfamethoxazole; six isolates were susceptible to erythromycin and clindamycin, and all were resistant to tetracycline, with results similar to those of $S$. pseudoporcinus. Two isolates were resistant to erythromycin and clindamycin with a diameter of $6 \mathrm{~mm}$ by the disc diffusion method, and MICs of $>256 \mu \mathrm{g} \mathrm{ml}^{-1}$ by Etest. The animal source of eight $S$. porcinus, isolated at the

Table 1. Characteristics of GBS, S. pseudoporcinus (SPP) and S. porcinus (SP)

GBS were identified with group B PathoDx antiserum.

\begin{tabular}{|lccc|}
\hline Test & $\begin{array}{c}\text { No. of GBS (\%) } \\
\text { [total } \boldsymbol{n}=\mathbf{1 1 8} \text { ] }\end{array}$ & $\begin{array}{c}\text { No. of SPP (\%) } \\
\text { [total } \boldsymbol{n}=\mathbf{1 5} \text { ] }\end{array}$ & $\begin{array}{c}\text { No. of SP (\%) } \\
\text { [total } \boldsymbol{n}=\mathbf{8} \text { ] }\end{array}$ \\
\hline Group B PathoDx & $118(100)$ & $14(93.3)$ & $4(50)$ \\
Group A, C, F and G* & NA & $0(0)$ & $0(0)$ \\
Narrow $\beta$-haemolysis & $116(98)$ & $0(0)$ & $0(0)$ \\
Large $\beta$-haemolysis & $0(0)$ & $15(100)$ & $8(100)$ \\
No $\beta$-haemolysis & $2(2)$ & $0(0)$ & $0(0)$ \\
Aesculin $\dagger$ & $1(1)$ & $15(100)$ & $6(75)$ \\
Bile aesculin $\dagger$ & NA & $0(0)$ & $0(0)$ \\
Mannitol $\dagger$ & $0(0)$ & $15(100)$ & $8(100)$ \\
Sorbitol $\dagger$ & $0(0)$ & $15(100)$ & $8(100)$ \\
Bacitracin resistance $\dagger$ & NA & $15(100)$ & $8(100)$ \\
CAMP test $\dagger$ & NA & $15(100) \ddagger$ & $7(87.5) \ddagger$ \\
PCR of $c f b$ gene & NA & $0(0) \S$ & $1(12.5)$ \\
\hline
\end{tabular}

NA, Not available.

${ }^{*}$ PathoDx.

$\dagger$ Incubation of $18-24 \mathrm{~h}$.

$\ddagger$ Slight increase of haemolysis.

§Eleven isolates tested. 
Table 2. Antimicrobial susceptibility of the 15 S. pseudoporcinus (SPP)

\begin{tabular}{|lccccc|}
\hline Antimicrobial agent & Susceptibility & No. of SPP & DD $(\mathbf{m m})$ & Etest $_{\left(\boldsymbol{\mu g ~ ~ ^ { - 1 }}\right.}$ ) & MIC $_{\mathbf{9 0}}$ \\
\hline Penicillin & $\mathrm{S}$ & 15 & $31-39$ & $0.008-0.06$ & 0.03 \\
Tetracycline & $\mathrm{R}$ & 0 & - & - & - \\
& $\mathrm{S}$ & 1 & 24.5 & 1 & 128 \\
Erythromycin & $\mathrm{R}$ & 14 & $6-12$ & $32-128$ & - \\
& $\mathrm{S}$ & 15 & $26.5-33$ & $0.06-0.12$ & 0.06 \\
Clindamycin & $\mathrm{R}$ & 0 & - & - & - \\
Vancomycin & $\mathrm{S}$ & 15 & $23-28$ & $0.03-0.06$ & 0.06 \\
& $\mathrm{R}$ & 0 & - & - & - \\
TMP-SMX & $\mathrm{S}$ & 15 & $18-24$ & $0.25-1$ & 1 \\
& $\mathrm{R}$ & 0 & - & - & - \\
& $\mathrm{S}$ & 15 & $16.9-42$ & - & - \\
& $\mathrm{R}$ & 0 & - & - & - \\
\hline
\end{tabular}

DD, Disc diffusion; MIC $_{90}$, MIC for $90 \%$ of strains; S, susceptible; R, resistant.

Faculté de Médecine Vétérinaire de l'Université de Montréal from 1995 to 2006, was swine for five of them and was unknown for the other three isolates.

S. pseudoporcinus was isolated in 3 different laboratories from 15 patients (13 in one hospital), 1 in 1997 and 1998, 3 in 2004, 4 in 2005 and 6 in 2006. All patients were pregnant women, aged 21 to 43 years. A total of 11 patients originated from the Caribbean Islands (10 from Haiti, 1 from Jamaica) and 4 from Africa (Cameroon, Ivory Coast, Benin and Angola). These women left their country of origin 3 months to 24 years earlier, with a median time of residence in Canada of 5 to 8 years. Of interest, patient 1 (Table 3) was a 24 -year-old woman, born in the province of Quebec, Canada, but her parents and sexual partner were Jamaicans. Chorioamnionitis was clinically diagnosed in patients 2, 3 and 9 (Table 3); no cultures were done at the time of diagnosis. Patients 2 and 3 delivered at 28 and 34 weeks of gestation, respectively. Patient 2 had two subsequent premature babies. The 12 other women had normal pregnancies and term deliveries.

At CHUM - Hôpital Saint-Luc, we reviewed the charts of 36 control women who delivered on the same day as the six women colonized by $S$. pseudoporcinus (patients 3 to 8 , Table 3) over the 8 month period. Five of the control patients originated from the Caribbean and sub-Saharan Africa (13.9\%). Seven control patients, one originating

Table 3. Epidemiological data on patients with documented S. pseudoporcinus

\begin{tabular}{|c|c|c|c|c|c|c|c|c|}
\hline $\begin{array}{l}\text { Patient } \\
\text { no. }\end{array}$ & $\begin{array}{l}\text { Year of positive culture } \\
\text { for } S \text {. pseudoporcinus }\end{array}$ & Sex & Age (years) & $\begin{array}{l}\text { Country of } \\
\text { origin }\end{array}$ & $\begin{array}{l}\text { No. of years outside } \\
\text { country of origin }\end{array}$ & Specimen & Chorioamnionitis & Baby \\
\hline 1 & 1997 & $\mathrm{~F}$ & 24 & Canada $^{*}$ & 24 & Vag rect & No & $\mathrm{T}$ \\
\hline 2 & 1998 & $\mathrm{~F}$ & 29 & Haiti & $\geqslant 5$ & Vag rect & Yes & $\mathrm{P}$ \\
\hline 3 & 2004 & $\mathrm{~F}$ & 29 & Haiti & 1.3 & Vag rect & Yes & $\mathrm{P}$ \\
\hline 4 & 2004 & $\mathrm{~F}$ & 43 & Haiti & 18 & Vag rect & No & $\mathrm{T}$ \\
\hline 5 & 2004 & $\mathrm{~F}$ & 21 & Cameroon & 3.5 & Vag rect & No & $\mathrm{T}$ \\
\hline 6 & 2005 & $\mathrm{~F}$ & 32 & Haiti & 4 & Vag rect & No & $\mathrm{T}$ \\
\hline 7 & 2005 & $\mathrm{~F}$ & 36 & Haiti & 8 & Vag rect & No & $\mathrm{T}$ \\
\hline 8 & 2005 & $\mathrm{~F}$ & 23 & Ivory Coast & 2.3 & Vag rect & No & $\mathrm{T}$ \\
\hline 9 & 2005 & $\mathrm{~F}$ & 32 & Haiti & 0.25 & Urine & Yes & $\mathrm{T}$ \\
\hline 10 & 2006 & $\mathrm{~F}$ & 40 & Benin & $\geqslant 10$ & Vag rect & No & $\mathrm{T}$ \\
\hline 11 & 2006 & F & 38 & Haiti & 5 & Vag rect & No & $\mathrm{T}$ \\
\hline 12 & 2006 & F & 36 & Haiti & 8 & Vag rect & No & $\mathrm{T}$ \\
\hline 13 & 2006 & F & 31 & Angola & 5 & Vag rect & No & $\mathrm{T}$ \\
\hline 14 & 2006 & $\mathrm{~F}$ & 40 & Haiti & 20 & Vag rect & No & $\mathrm{T}$ \\
\hline 15 & 2006 & F & 32 & Haiti & 11 & Vag rect & No & $\mathrm{T}$ \\
\hline
\end{tabular}

*This patient was born in Quebec, Canada, but her parents and sexual partner were Jamaicans.

F, female; P, baby born prematurely ( $<37$ weeks of gestation); T, baby born at term; Vag rect, vaginorectal swab specimen. 
from the Caribbean, were excluded because a vaginorectal swab specimen was not obtained for GBS culture. One woman colonized by $S$. pseudoporcinus was excluded because there were no control patients for her. Therefore, 29 control patients were compared to 5 women colonized by $S$. pseudoporcinus (patients 4 to 8 , Table 3 ); 2 to 14 (median of 3) control patients were documented for each of the cases. A total of 4 of the 29 women without $S$. pseudoporcinus and 5 of the 5 women with $S$. pseudoporcinus originated from the Caribbean and sub-Saharan Africa $(P=0.00045)$. The five women with $S$. pseudoporcinus had left their country of origin 2.3 to 18 years previously (median 4 years) and the four women from the Caribbean or sub-Saharan Africa without $S$. pseudoporcinus had left their country of origin 5 to 30 years previously (median 19 and 24 years). Chorioamnionitis was clinically diagnosed in none of the 5 women with S. pseudoporcinus and in 9 of the 29 women without $S$. pseudoporcinus $(P=0.29)$. None of the 5 women with $S$. pseudoporcinus and 1 of the 29 women without $S$. pseudoporcinus delivered prematurely (defined as less than 37 weeks of gestation) at 32 weeks 6 days $(P=1.0)$.

The human group $\mathrm{C} 1 \mathrm{~S}$. porcinus strains reported by Facklam et al. (1995) might very well be S. pseudoporcinus, since they were biochemically indistinguishable from the animal $S$. porcinus strains and, as currently reported, they were mainly isolated from the genitourinary tract of women (Facklam et al., 1995; Duarte et al., 2005). The group $\mathrm{C} 1 \mathrm{~S}$. porcinus animal isolate used as the reference strain for this antiserum was very different from human isolates in the molecular studies of Duarte et al. (2005), so this group $\mathrm{C} 1$ animal strain may not be the same species as the group $\mathrm{C} 1$ human isolates of the $\mathrm{CDC}$ collection. The fact that all the women documented in our study were from two different Caribbean countries and from three sub-Saharan African countries is most fascinating. The origin of these strains is not clear. That this new species was so homogeneous on 16S rRNA sequencing as it was in the molecular studies of Duarte et al. (2005) is very surprising. The significant association of this new species with these ethnic groups should be investigated. No pathogenic role was clearly associated with our human isolates, but cultures were not done for the women with chorioamnionitis and the number of isolates was low. A clear pathogenic role of group $\mathrm{C} 1 \mathrm{~S}$. porcinus has been reported by others (Facklam et al., 1995; Duarte et al., 2005). S. pseudoporcinus and S. porcinus strains might be falsely identified as GBS, but the wide $\beta$-haemolysis, positive aesculin and acid produced in mannitol and sorbitol broths will distinguish the first two Streptococcus species from the last one at a very low cost. The CAMP test is not useful for differentiating GBS from $S$. pseudoporcinus: in 1995, Facklam et al. reported that 8 of their 13 human $S$. porcinus strains were CAMP-positive (Facklam et al., 1995), and our S. pseudoporcinus showed a slight increase in $\beta$-haemolysis with this test. If human or animal $S$. porcinus has a CAMP factor, it should be genetically different from that of GBS, since $c f b$ PCR was negative for 18 of our 19 isolates tested. Thompson and Facklam (1997) reported a study of $30 \mathrm{~S}$. porcinus with 13 kits for agglutination of $\beta$-haemolytic Streptococcus (12 commercial antisera and 1 antiserum from the CDC). They did not find cross-reactions with nine group A, C, D, F and $\mathrm{G}$ antisera. The 13 group $\mathrm{B}$ antisera showed cross-reactions for 3 to $80 \%$ (median $33 \%$ ) of the 30 S. porcinus isolates tested. The authors found a common antigenic entity between GBS and S. porcinus (Thompson \& Facklam, 1997). Fourteen of our fifteen S. pseudoporcinus revealed positive agglutination with PathoDx GBS antiserum, but no isolate gave agglutination with GBS antiserum Streptex (Bekal et al., 2006; unpublished results). In the literature, commercial PCR for the identification of GBS was not studied with $S$. porcinus strains, and this species was not included for specificity evaluation (Danbing et al., 2000).

The increased number of $S$. pseudoporcinus isolates documented in the province of Quebec, Canada, from 1997 to 2006, seems to be related to improvements in the identification of this bacterium and, since 2002, to universal prenatal screening for GBS, more than to an emergence of this pathogen. So far, the pathogenic role and prevalence of $S$. pseudoporcinus in humans need further study, and may be underestimated. Even if $16 \mathrm{~S}$ rRNA sequencing is needed to differentiate $S$. pseudoporcinus from S. porcinus, a Streptococcus identified biochemically as S. porcinus and isolated from the genitourinary tract of a woman is likely to be $S$. pseudoporcinus.

Interestingly, during January to June 2007 at CHUM Hôpital Saint-Luc, a 34-year-old pregnant woman, originating from sub-Saharan Africa, had S. pseudoporcinus isolated from a vaginorectal swab specimen (unpublished results).

\section{ACKNOWLEDGEMENTS}

We thank the personnel of the bacteriology section of the medical microbiology laboratory of CHUM - Hôpital Saint-Luc for technical assistance, and Dr Jean Vincelette for his critical reading of the manuscript and statistical data analysis.

\section{REFERENCES}

Bekal, S., Gaudreau, C., Laurence, R. A., Simoneau, E. \& Raynal, L. (2006). Streptococcus pseudoporcinus sp. nov., a novel species isolated from the genitourinary tract of women. J Clin Microbiol 44, 2584-2586.

CLSI (2005). Performance Standards for Antimicrobial Susceptibility Testing, 15th informational supplement, M100-S15, vol. 25, no. 1. Wayne, PA: Clinical and Laboratory Standards Institute.

Collins, M. D., Farrow, J. A. E., Katic, V. \& Kandler, O. (1984). Taxonomic studies on streptococci of serological groups E, P, U and V: description of Streptococcus porcinus sp. nov. Syst Appl Microbiol 5, 402-413.

Colman, G. \& Ball, L. C. (1984). Identification of streptococci in a medical laboratory. J Appl Bacteriol 57, 1-14. 
Danbing, K. E., Ménard, C., Picard, F. J., Boissinot, M., Ouellette, M., Roy, P. H. \& Bergeron, M. G. (2000). Development of conventional and real-time PCR assays for the rapid detection of group B streptococci. Clin Chem 46, 324-331.

Duarte, R. S., Barros, R. R., Facklam, R. R. \& Teixeira, L. M. (2005). Phenotypic and genotypic characteristics of Streptococcus porcinus isolated from human sources. J Clin Microbiol 43, 4592-4601.

Duma, R. J., Weinberg, A. N., Medrek, T. F. \& Kunz, L. J. (1969). Streptococcal infections. A bacteriologic and clinical study of streptococcal bacteremia. Medicine 48, 87-127.

Euzéby, J. (2007). List of new names and new combinations previously effectively, but not validly, published. Int J Syst Evol Microbiol 57, 893-897.

Facklam, R., Elliott, J., Pigott, N. \& Franklin, A. R. (1995). Identification of Streptococcus porcinus from human sources. J Clin Microbiol 33, 385-388.
Martin, C., Fermeaux, V., Eyraud, J. L. \& Aubard, Y. (2004). Streptococcus porcinus as a cause of spontaneous preterm human stillbirth. J Clin Microbiol 42, 4396-4398.

Parker, M. T. \& Ball, L. C. (1976). Streptococci and aerococci associated with systemic infection in man. J Med Microbiol 9, 275-302.

Rallu, F., Barriga, P., Scrivo, C., Martel-Laferrière, V. \& Laferrière, C. (2006). Sensitivities of antigen detection and PCR assays greatly increased compared to that of the standard culture method for screening for group B streptococcus carriage in pregnant women. J Clin Microbiol 44, 725-728.

Thompson, T. \& Facklam, R. (1997). Cross-reactions of reagents from streptococcal grouping kits with Streptococcus porcinus. J Clin Microbiol 35, 1885-1886.

Wessman, G. E. (1986). Biology of the group E streptococci: a review. Vet Microbiol 12, 297-328. 